\title{
Application of Photovoltaic Power Generation System in Military Systems
}

\author{
Xinrui Wang ${ }^{1, a^{*}}$, Long $\mathrm{He}^{1}$, Changbin $\mathrm{Ju}^{2, \mathrm{~b}}$ \\ ${ }^{1}$ No.208 Research Institute of China Ordnance Industries, China \\ ${ }^{2}$ Institute of Electrical Engineering, Chinese Academy of Sciences, China \\ aXinruii@163.com, bJCB@mail.iee.ac.cn
}

\section{Keywords: Application, Photovoltaic, Military Systems}

Abstract. Photovoltaic power generation because of the advantages of no noise, no pollution characteristics, but also has wide application in the military field, this paper first reviews the current photovoltaic power generation applications in public military facilities, military soldier equipment, small military reconnaissance equipment, discusses the advantages and disadvantages of photovoltaic power generation in the military should be used in the design, finally an island information point of PV and ocean energy and combined energy supply energy supply scheme.

\section{Introduction}

Energy is the power of the progress of human society is the bottleneck of restricting the human development. Photovoltaic power generation appear to offer a no noise, no pollution and clean energy for the human, the current photovoltaic power generation has become an important alternative energy in the human energy systems. There are also widely used in the military field, photovoltaic PV system to provide building clean energy widely used in American military base for military utility, has not been large-scale application in Chinese[1-3]; characteristics of no noise in the use of photovoltaic power generation system for individual soldier, can provide a stable energy range; in the small military reconnaissance in the power source equipment, photovoltaic power generation can be used as the ideal equipment[4-6], the realization of military, commercial investigation purpose[7]. According to the military information point of uninhabited islands, this paper designs a kind of island information point of photovoltaic power generation and ocean energy power generation combined energy supply energy supply scheme.

\section{Provide clean energy in military utilities}

In USA permanent military bases, fixed military facilities gradually into the daily government public construction management, therefore the energy supply fixed military facilities in general are also incorporated into the government contract energy plan. Rooftop PV projects more and more are being built in the military facilities of roof.

In 2014 July the United States PE company to build the biggest US building photovoltaic system for the Navy and Marine Corps base in Hawaii on the island of Oahu.

The project consists of ten groups of rooftop photovoltaic systems and four ground or elevated photovoltaic system, distributed in three different bases. In the first years after completion, these power system can save 1600000 dollars for taxpayers. Electric energy is equivalent to 54000 barrels of oil produced in Hawaii to provide the photovoltaic power generation system of electric energy, can be used to power more than 5000 homes.

PE company will be in the joint base Pearl Harbor Hickam (JBPHH) where the Huaipiao Peninsula to build 3 sets of rooftop photovoltaic system and 1 groups of terrestrial photovoltaic system, set up 6 groups of rooftop photovoltaic systems and 2 sets of elevated photovoltaic system in Hawaii the United States Marine Corps base, camp construction group 1 rooftop photovoltaic system and photovoltaic system in 1 groups of viaduct the island of Aiea smith. 
The PV array power system installed capacity of 17 megawatts, is the United States Navy in the Pacific region's largest photovoltaic array project, can work continuously for 25 years. Figure 1 is Photovoltaic power generation system in the military base.

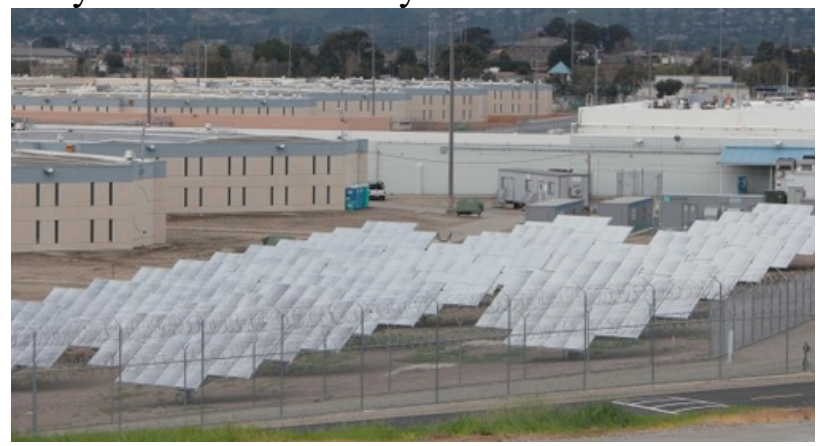

Fig. 1 The photovoltaic power generation system in the military base.

Two diesel generator has been in use since the last century 60's Shenyang Sanshan Island, not only noise, heavy pollution, high failure rate, and every power less than 2 hours, at the beginning of 2011 in Sanshandao construction of solar photovoltaic power station.

Chinese government plans to use 2 to 3 years time, the priority is located in cold, high humidity, plateau area, the remote location, poor environment of the 100 boundary defense post and 10 military airports new solar photovoltaic power station power supply system, provides a stable environment for the grassroots units. Figure 2 is a photovoltaic power generation system on the island.

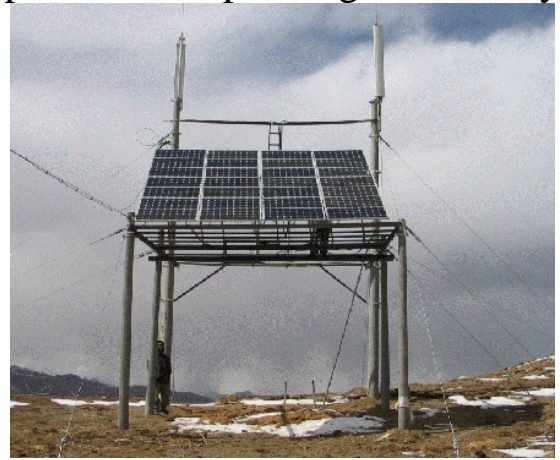

Fig.2 A photovoltaic power generation system on the island

\section{Provide a stable energy supply to individual equipment}

With the development of science and technology, the soldier becomes more and more important in the battlefield, soldier system has become an important technology of armed soldiers to carry out the task of supporting the battlefield. In individual system electronic equipment for large application, in order to reduce the burden of the soldiers, the electronic equipment power supply capacity is limited, must provide reliable charging scheme for the. Figure 3 is a single soldier system diagram.

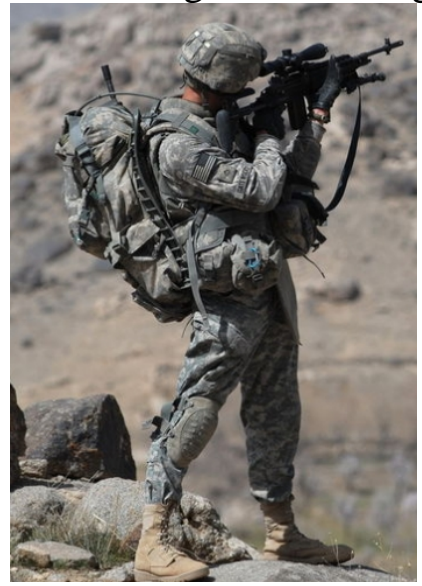

Fig.3 A single soldier system diagram 
Figure 4 is a mobile solar system.Through the portable photovoltaic panels can be moved, with power electronic charging device, providing an endurance of individual power supply system.

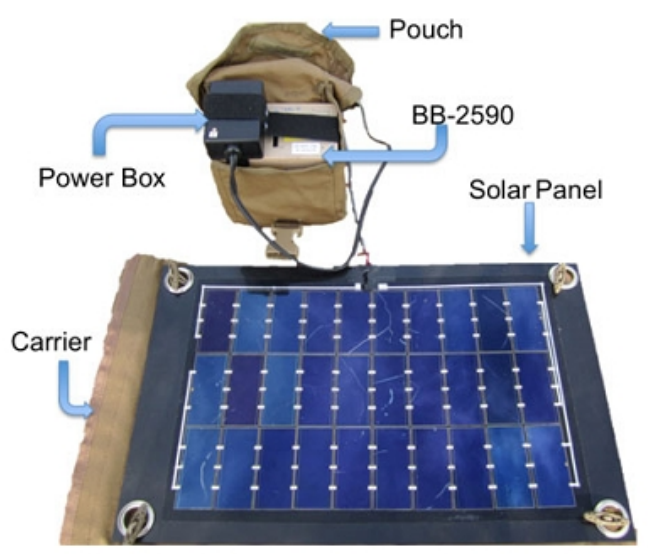

Fig.4 A mobile solar system

\section{Provide enough power for the small military reconnaissance equipment}

Outer space satellites and other detection equipment, is the earliest application scene of photovoltaic power generation, has accumulated rich experience, with the development of the aerospace industry, photovoltaic power generation has become the main power supply form among them, satellite, the Mars Exploration Rover and other equipment mainly rely on photovoltaic power generation to provide carry action. Figure 5 is the Mars Exploration Rover system.

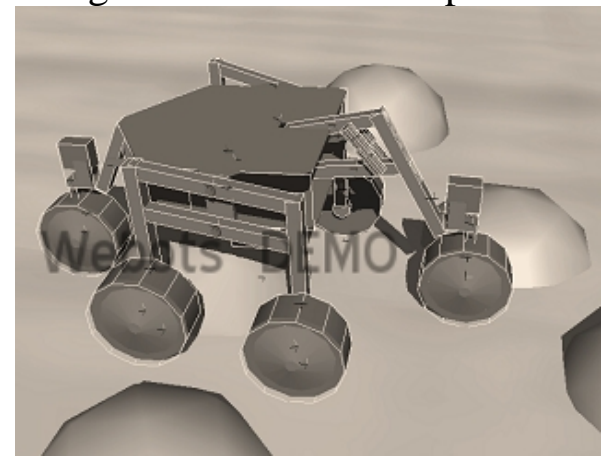

Figure 5 A the Mars Exploration Rover system

In 2013 August AeroVironment Company designed a PumaAE UAV, UAV combined before the development of a hybrid model of fuel cell power system, can fly in the air for 9 hours. Plane weighs 13 pounds, without transmitting station and landing platform, in the military, public security, business customers are very promising. It uses solar power to extend battery life, the PumaAE device than the solar battery to extend from two to 3 hours. PumaAE device of 2008 was USA military authorities to intercept the intelligence, surveillance and reconnaissance behavior. Figure 6 is a PumaAE UAV system diagram.

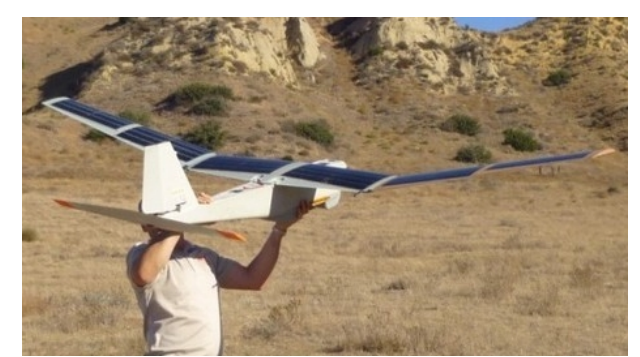

Fig.6 A PumaAE UAV system diagram

The solar PumaAE device in the air for 9 hours and 11 minutes. Ultrathin GaAs solar cell device has a battery of GaAs solar cell can generate enough power generation for the aircraft to fly long distances, solar powered aircraft to increase the weight almost negligible. 


\section{A photovoltaic power generation and ocean energy power generation combined energy supply scheme used in information points of islands}

Photovoltaic power generation has the widespread application in the island of off grid power system. But the characteristics of photovoltaic power fluctuation cycle is short, the night unable to power generation, photovoltaic power generation can not be independent for unmanned Island information point system to provide reliable energy. The unmanned island from the mainland of distance, inconvenient maintenance, must have a reliable design of the function. Tidal power is a stable and predictable forms of generation, can be used as a complementary type photovoltaic power generation.

Tidal power is a kind of hydraulic power form, using mobile tidal flow, or lifting tidal sea, from which to obtain energy. The tides generally occurs in the morning or evening, photovoltaic power is just enough to make up for lack of time, the fluctuations of PV power. There will also be a small power stable energy output in the night tidal power, enough unmanned Island information point of energy demand.

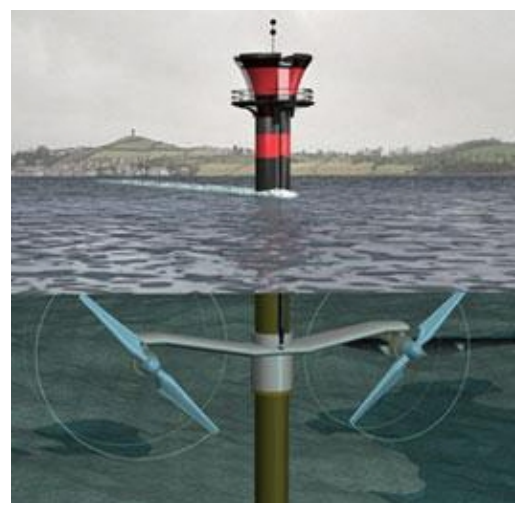

Fig.7 Tidal power principle

\section{Conclusion}

This paper reviews the application scene of photovoltaic power generation in the military field, photovoltaic power generation due to no noise, no pollution characteristics, also does not have the source points are not obvious outward radiation energy, photovoltaic power generation can be used as a stable, reliable, and can be invisible power supply scheme in the military field. Because of the information point unmanned island need 24 hours of work, in the configuration storage systems, only rely on is unable to provide a stable supply of photovoltaic energy. This paper describes the design of photovoltaic power generation and sea could provide reliable power function of tidal power combining system for unmanned Island Information point.

\section{Reference}

[1] R. Tatavarti, G. Hillier, A. Dzankovic, G. Martin, F. Tuminello R. Navaratnarajah, G. Du, D. P. Vu, and N. Pan, "Lightweight, low cos GaAssolarcellson4 epitaxialliftoff(ELO)wafers,"inProc.33rdIEEE PhotovoltaicSpecialists Conf.,May 2008,pp.1-4.

[2] R.Tatavarti,A.Wibowo,G.Martin,F.Tuminello,C.Youtsey,G.Hillier N. Pan, M. W. Wanlass, and M. Romero, "InGaP/GaAs/InGaAs inverted

metamorphic(IMM)solarcellson4epitaxialliftedoff(ELO)wafers, "in Proc. $35^{\text {th }}$ IEEE Photovoltaic

Spec.Conf.,Jun.2010,pp.002125-002128

[3] C. Gueymard, Simple Model of the Atmospheric Radiative Transfer ofSunshine(SMARTS), ver.

2.9.5,2009

[4] [Online].http://www.bren-tronics.com/bt-70791a.html,lastaccessFeb.2, 2012. 
[5] [Online]. http://en.wikipedia.org/wiki/MOLLE, last access Feb. 2, 2012.

[6] Y. Kishi, H. Inoue, H. Tanaka, S. Kouzuma, K. Murata, S. Sakai, M. Nishikuni, K. Wakisaka, H. Shibuya, H. Nishiwaki, A. Takeoka, and Y. Kuwano, "New type of ultralight flexible a-Si solar cell and its appli- cationonanairplane,"inProc.22ndIEEE Photovoltaic Spec.Conf.,Oct. 1991, pp. 1213-1218.

[7] J.Park,H.Ham,J.Lee,andT.Kim, "Thin film encapsulation for flexible organic solar cells," in Proc. 35th IEEE Photovoltaic Spec. Conf., Jun.2010,pp.001657-001659. 